\title{
Hydrogen Protects Mice from Radiation induced Thymic Lymphoma in BALB/c mice
}

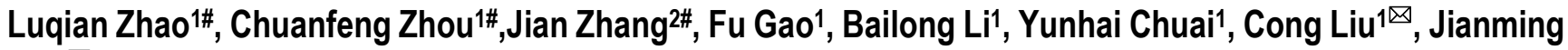 \\ Cai ${ }^{1 凶}$
}

1. Department of Radiation Medicine, Second Military Medical University, Xiangyin Road, Shanghai 200433, PR China.

2. Department of Surgery, Changzheng Hospital, Second Military Medical University, Xiangyin Road, 200433, Shanghai, PR China.

\# These authors contributed equally to this work.

$\triangle$ Corresponding author: Jianming Cai \& Cong Liu. Address: Department of Radiation Medicine, Second Military Medical University; 800, Xiangyin Road 200433, Shanghai; P.R. China Fax: +86-21-81871150. E-mail: caijianming882003@163.com \& victorliu20102020@smmu.edu.cn.

(C) Ivyspring International Publisher. This is an open-access article distributed under the terms of the Creative Commons License (http://creativecommons.org/ licenses/by-nc-nd/3.0/). Reproduction is permitted for personal, noncommercial use, provided that the article is in whole, unmodified, and properly cited.

Received: 2011.03.19; Accepted: 2011.03.20; Published: 2011.03.25

\begin{abstract}
lonizing radiation (IR) is a well-known carcinogen, however the mechanism of radiation induced thymic lymphoma is not well known. Moreover, an easy and effective method to protect mice from radiation induced thymic lymphoma is still unknown. Hydrogen, or $\mathrm{H}_{2}$, is seldom regarded as an important agent in medical usage, especially as a therapeutic gas. Here in this study, we found that $\mathrm{H}_{2}$ protects mice from radiation induced thymic lymphoma in BALB/c mice.
\end{abstract}

Key words: Ionizing radiation, thymic lymphoma

\section{Introduction}

Ionizing radiation (IR) is a well-known carcinogen for various human tissues and a complete carcinogen that is able to both initiate and promote tumor progression $[1,2,3]$. The mechanism for this promotion is poorly understood, but studies of mouse thymic lymphomas provide some hints $[2,4,5,6,7,8]$. Indeed, studies of radiation-induced mouse thymic lymphomas, one of the classic models in radiation carcinogenesis, demonstrated that multi-steps and many factors, like Ras, Pten and Fas, were involved in radiation-induced carcinogenesis [4,7]. Our previous studies showed that ERK1/2, STAT3 and SHP-2 are also involved in radiation induced thymic lymphoma formation in BALB/c mice [9]. However, an easy and effective method to protect mice from radiation-induced thymic lymphoma is still not well known $[1,10]$.
Hydrogen $\left(\mathrm{H}_{2}\right)$, the most abundant chemical element in the universe (constituting approximately $75 \%$ of the universe's elemental mass), is seldom regarded as an important agent in medical usage, especially as a therapeutic gas. However, many recent studies by our lab and other labs provided evidence that $\mathrm{H}_{2}$ gas has powerful therapeutic and preventive effects for many diseases $[11,12,13]$. Ohsawa et al. found that molecular $\mathrm{H}_{2}$ could selectively reduce cytotoxic reactive oxygen species, such as hydroxyl radicals in vitro and exert therapeutic antioxidant activity in a rat middle cerebral artery occlusion model in vivo [11]. Since hydroxyl is very strong oxidants that react indiscriminately with nucleic acids, lipids and proteins resulting in DNA fragmentation, lipid peroxidation and protein inactivation, they are also the main mediators of radiation damage [12]. We 
hypothesized and showed by experimental studies that $\mathrm{H}_{2}$ treatment could protect cultured cells and mice from radiation damage $[12,13,14]$. In those studies, we used a single high dose model to find that $\mathrm{H}_{2}$ is a novel protective gas on radiation induced injuries. Importantly, those previous studies also showed that $\mathrm{H}_{2}$-rich saline/water is safe, easy to administer and cost-effective $[13,14]$.

In this study, we used a split dose radiation-induced thymic lymphoma model in BALB/c mice to test the potential role of $\mathrm{H}_{2}$ on radiation induced carcinogenesis in a method very similar to our previously studies $[9,13,14]$.

\section{Materials and Experimental Design}

Radiation induced thymic lymphoma model was described by many groups and our previous studies $[4,5,9]$. In detail, male wild-type BALB/c mice, 5-6 weeks of age, were purchased from Chinese academy of science (Shanghai, China) and A ${ }^{60} \mathrm{Co}$ irradiator was introduced for total-body ionizing irradiation as de- scribed in our previous work $[9,12,13,14,15]$. Four weekly sub-lethal doses of 1.75 Gy gamma-ray irradiation were delivered to 5-6 week old BALB/c mice at a dose rate of $0.58 \mathrm{~Gy} / \mathrm{min}$ as described previously [9]. Only two groups were used in this study: the $\mathrm{H}_{2}$-rich saline group $\left(\mathrm{H}_{2}(+)\right.$ group) or normal saline control $\left(\mathrm{H}_{2}(-)\right.$ group $)$ as described previously $[13,14]$. Themice from these two groups were intraperitonealy injected with $\mathrm{H}_{2}$-rich saline $\left(\mathrm{H}_{2}(+)\right.$ group) or normal saline $\left(\mathrm{H}_{2}(-)\right.$ group) 5 minutes before each irradiation respectively as we described detailed in our previous work $[13,14]$.

\section{Results and Discussion}

We found that $\mathrm{H}_{2}$ treatment significantly increased the survival rate of mice 30 weeks' after split dose radiation (Figure $1 \mathrm{~A}, \mathrm{P}<0.05$ ). This datum is consistent with our previous studies that $\mathrm{H}_{2}$ treatment could protect cultured cells and mice from radiation damage $[12,13,14]$.
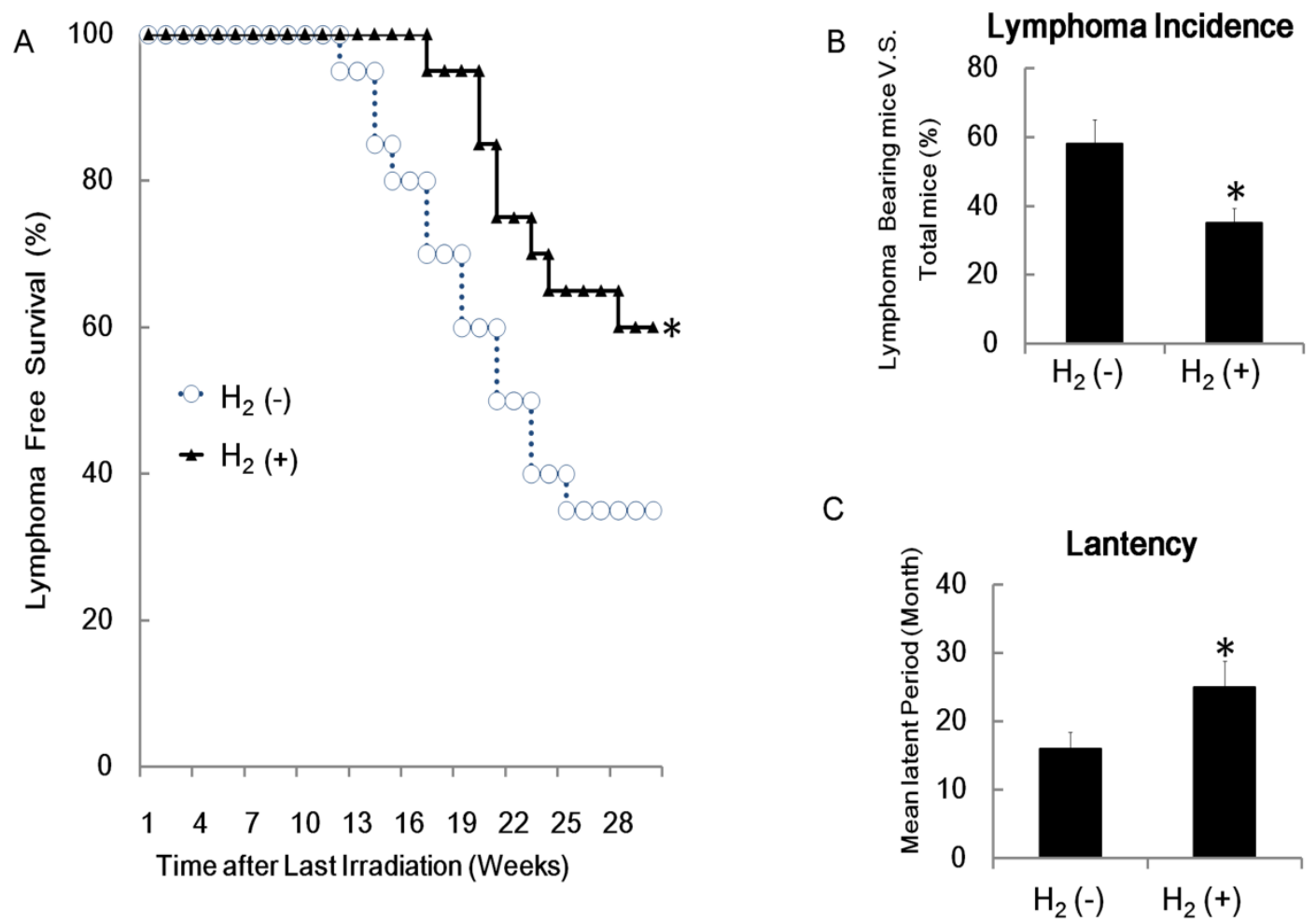

Figure I. Hydrogen treatment protected BALB/c mice from radiation-induced thymic lymphoma. Four weekly sub-lethal doses of $1.75 \mathrm{~Gy}$ gamma-ray irradiation were delivered to 4 week old BALB/c mice at a dose rate of $0.58 \mathrm{~Gy} / \mathrm{min}$ as described previously [9]. These mice were intraperitonealy injected with either $\mathrm{H}_{2}$-rich saline $\left(\mathrm{H}_{2}\right.$ group, $\left.\mathrm{H}_{2}(+)\right)$ or normal saline (Control group, $\left.\mathrm{H}_{2}(-)\right) 5$ minutes before each irradiation as described previously [13, 14]. Panel A; Survival curve analysis of control and $\mathrm{H}_{2}$ treated mice after split irradiation $(\mathrm{N}=40)$. Panel $\mathrm{B}$; tumor incidence at 20 weeks post last irradiation was analyzed by histological study ( $N=20,3$ repeats). Panel C; Mean latent Period was calculated ( $N=20,3$ repeats). 
A

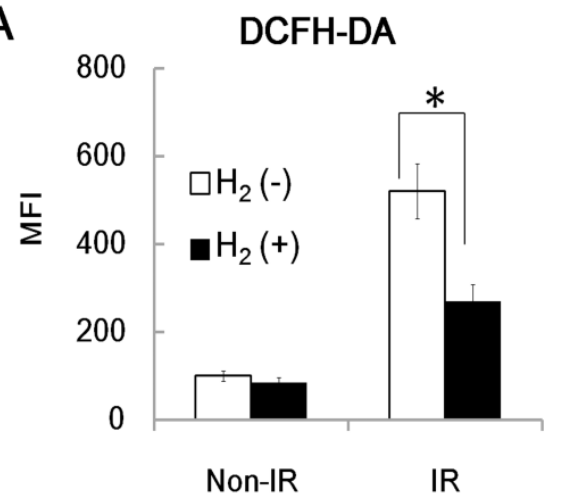

C

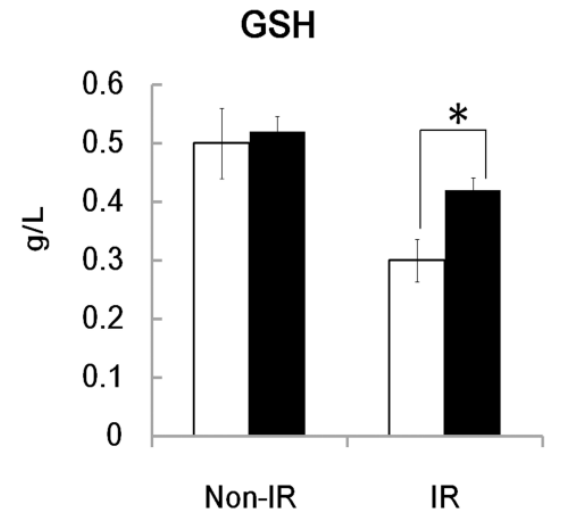

B

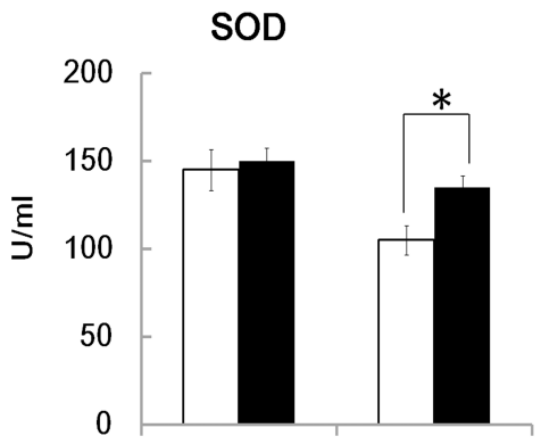

Non-IR

IR

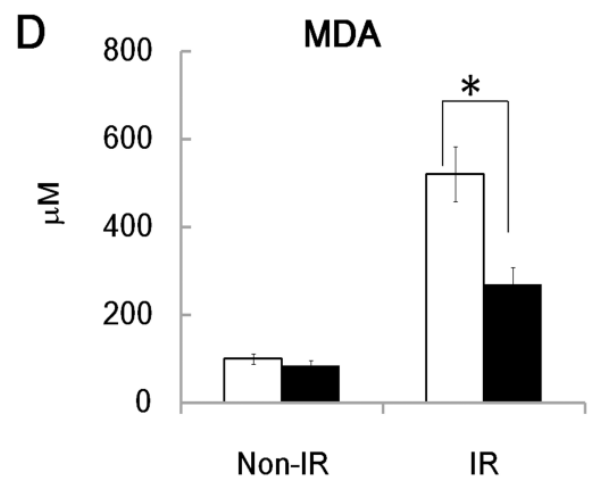

Figure 2. $\mathrm{H}_{2}$ pre-treatment reduced split radiation- induced ROS levels. BALB/c mice, 5-6 weeks of age, were subjected with IR (IR group) or without IR (Non-IR group). IR protocol was the four weekly sub-lethal doses of I.75 Gy gamma-ray irradiation at a dose rate of $0.58 \mathrm{~Gy} / \mathrm{min}$ [9]. These mice were also intraperitonealy injected with $\mathrm{H}_{2}$-rich saline $\left(\mathrm{H}_{2}(+)\right.$ group $)$ or with normal saline $\left(\mathrm{H}_{2}(-)\right.$ group) 5 minutes before each irradiation respectively as we described in detail in our previous work $[13,14]$. Then 4 hours after the last irradiation, PBMC and serum from these mice were prepared and the ROS levels were measured with our published methods ( $N=6,3$ repeats). Panel A: PBMC from BALB/c mice, with or without IR, with or without $\mathrm{H}_{2}, 4$ hours after last IR were prepared and subjected to FACS assay to detect the DCFH-DA ROS level. MFI: Mean Fluorescence Intensity; ( $N=6,3$ repeats). Panel B-D; Serum from BALB/c mice, with or without IR, with or without $\mathrm{H}_{2}$, 4 hours after last IR were prepared and subjected to ELISA assay for detection of SOD, GSH and MDA level with or our published method [I3, I4]. B: SOD; C: GSH; D: MDA; (N=6, 3 repeats).

However, the radiation-induced thymic lymphoma rate in the $\mathrm{H}_{2}(+)$ group was significantly lower than in the control group (Figure $1 \mathrm{~B} \mathrm{P}<0.05$ ) and $\mathrm{H}_{2}$ treatment significantly increased the latency of lymphoma development after the split dose irradiation (Figure 1C). These data indicated that $\mathrm{H} 2$ protects mice from radiation induced thymic lymphoma in BALB/c mice.

The detrimental effects of IR on biological tissues can be mediated via increased production of free radicals and reactive oxygen species (ROS) and the ROS system have been found to play important role in the induction of cancers $[1,8,16]$.

To explore the potential role of $\mathrm{ROS}$ in $\mathrm{H}_{2}$ in- duced protection of radiation induced carcinogenesis, we used different methods to detect changes in intracellular and extracellular ROS levels in $\mathrm{H}_{2}$ treated mice and control mice $4 \mathrm{~h}$ after the last irradiation [13]. Intracellular ROS levels in peripheral blood mononuclear cells (PBMC) from irradiated and control mice were assessed using FACS analysis with DCFH-DA (2'7'di-chlorofluorescein diacetate), which converts to highly fluorescent DCF in the presence of intracellular ROS. As shown in Figure 2A, ROS levels were much lower in the irradiated $\mathrm{H}_{2}$ group than in the irradiated control mice. Similar results were also found for ROS levels in extracellular serum. Serum SOD (Superoxide dismutase) and total GSH (Glutathione) concentra- 
tions at $4 \mathrm{~h}$ after the last irradiation in the $\mathrm{H}_{2}$ group were significantly higher than that of the control group, while MDA (Malondialdehyde) concentrations in the $\mathrm{H}_{2}$ group were significantly lower than that of the control group (Figure 2B, 2C and 2D). These results indicate that the $\mathrm{H}_{2}$ pre-treated groups showed an increased antioxidant status, consistent with our previous studies that showed that $\mathrm{H} 2$ could reduce radiation-induced free radical damage to DNA $[13,14]$.

Radiation therapy is now a routine treatment for certain types of cancer and over 20 percent of cancer patients will require radiation therapy during the treatments of their disease [16,17]. Radiation itself can induce many types of cancers, especially leukemia and lymphomas, but few simple protective methods have been found.

To the best of our knowledge, this may be the first report describing treatment with $\mathrm{H}_{2}$, which reduced the risk of radiation-induced carcinogenesis in the BALB/c mouse model. While the therapeutic effectiveness of $\mathrm{H}_{2}$ treatment on radiation carcinogenesis needs further study, this work provides some novel experimental evidence for the use of $\mathrm{H}_{2}$ in radiation therapy. Since it is safe, easy to administer and cost-effective, it could not only protect against radiation induced death $[12,13,14]$, but also attenuate the rate of radiation induced carcinogenesis.

\section{Conclusion}

In conclusion, our data indicates that $\mathrm{H}_{2}$ protects mice from radiation induced thymic lymphoma in $\mathrm{BALB} / \mathrm{c}$ mice.

\section{Acknowledgment}

We thank Dr. Cindy Savage and Trip Barthel M.A for help editing of the manuscript.

This work was supported in part by the grants from National Natural Science Foundation of China (No. 31070761 and No.81072241) and by the grants from Natural Science Foundation of Shanghai, China (No. 11ZR1446400 and No.09ZR1439400).

\section{Conflict of Interests}

None.

\section{References}

1. Little JB. Radiation carcinogenesis. Carcinogenesis 2000;21: 397-404.

2. Potworowski EF, Gagnon F, Beauchemin C, St Pierre Y. Dendritic cells prevent radiation-induced thymic lymphoma. Leukemia 1996;10: 1639-1647.

3. Shin SC, Kang YM, Kim HS. Life span and thymic lymphoma incidence in high- and low-dose-rate irradiated AKR/J mice and commonly expressed genes. Radiat Res 2010;174: 341-346.
4. Villa-Morales M, Santos J, Fernandez-Piqueras J. Functional Fas (Cd95/Apo-1) promoter polymorphisms in inbred mouse strains exhibiting different susceptibility to gamma-radiation-induced thymic lymphoma. Oncogene 2006;25: 2022-2029.

5. Santos J, Montagutelli X, Acevedo A, Lopez P, Vaquero C, et al.. A new locus for resistance to gamma-radiation-induced thymic lymphoma identified using inter-specific consomic and inter-specific recombinant congenic strains of mice. Oncogene 2002;21: 6680-6683.

6. Humblet C, Defresne MP, Greimers R, Rongy AM, Boniver J. Further studies on the mechanism of radiation induced thymic lymphoma prevention by bone marrow transplantation in C57BL mice. Leukemia 1989;3: 813-818.

7. Utsuyama M, Hirokawa K. Radiation-induced-thymic lymphoma occurs in young, but not in old mice. Exp Mol Pathol 2003;74: 319-325.

8. Siegler R, Harrell W, Rich MA. Pathogenesis of radiation-induced thymic lymphoma in mice. J Natl Cancer Inst 1966;37: 105-121.

9. Fu Z, Huang D, Cai J, Chen Q, Han L, et al.. Expression changes of ERK1/2, STAT3 and SHP-2 in bone marrow cells from gamma-ray induced leukemia mice. J Radiat Res (Tokyo) 2006;47: 121-130.

10. Pogribny I, Koturbash I, Tryndyak V, Hudson D, Stevenson $\mathrm{SM}$, et al.. Fractionated low-dose radiation exposure leads to accumulation of DNA damage and profound alterations in DNA and histone methylation in the murine thymus. Mol Cancer Res 2005;3: 553-561.

11. Ohsawa I, Ishikawa M, Takahashi K, Watanabe M, Nishimaki $\mathrm{K}$, et al.. Hydrogen acts as a therapeutic antioxidant by selectively reducing cytotoxic oxygen radicals. Nat Med 2007;13: 688-694.

12. Liu C, Cui J, Sun Q, Cai J. Hydrogen therapy may be an effective and specific novel treatment for acute radiation syndrome. Med Hypotheses 2010;74: 145-146.

13. Qian L, Cao F, Cui J, Huang Y, Zhou X, et al.. Radioprotective effect of hydrogen in cultured cells and mice. Free Radic Res 2010;44: 275-282.

14. Qian L, Cao F, Cui J, Wang Y, Huang Y, et al.. The potential cardioprotective effects of hydrogen in irradiated mice. J Radiat Res (Tokyo) 2010;51: 741-747.

15. Liu C, Lin J, Zhao L, Yang Y, Gao F, et al.. Gamma-ray Irradiation Impairs Dendritic Cell Migration to CCL19 by Down-regulation of CCR7 and Induction of Cell Apoptosis. Int J Biol Sci 2011;7: 168-179.

16. Barcellos-Hoff MH, Park C, Wright EG. Radiation and the microenvironment - tumorigenesis and therapy. Nat Rev Cancer 2005;5: 867-875.

17. Tannenbaum B, Mofunanya T, Schoenfeld AR. DNA damage repair is unaffected by mimicked heterozygous levels of BRCA2 in HT-29 cells. Int J Biol Sci 2007;3: 402-407. 